\title{
Anesthetic management of a parturient for combined cesarean section and surgical removal of pituitary tumor -A case report-
}

\author{
Ji-hyun Chung, Jeong-Ho Rho, Tae-Hyeng Jung, Seung-Cheol Cha, Han-Kil Jung, Cheong Lee, and \\ Seong-Chang Woo
}

Department of Anesthesiology and Pain Medicine, Eulji University Hospital, Daejeon, Korea

A 40-year-old woman was referred to our hospital because of bitemporal hemianopsia at 23 weeks of gestation. A brain magnetic resonance imaging showed a pituitary tumor having suprasellar extension. At 30 weeks of gestation, she complained of rapidly deteriorating vision and bitemporal hemianopsia in both eyes and the ensuing radiological examination revealed increased tumor size, displaced tumor location and compressed optic chiasm. The cesarean section was performed at 31 weeks and 3 days of gestation and simultaneous surgical removal of pituitary tumor was carried out due to the risk of irreversible blindness. Anesthetic management for combined cesarean section and brain surgery can be more complex and challenging for anesthesiologists, and the aim was to achieve both the control of intracranial pressure and fetal well being at the same time. In this case, maternal outcome was somewhat improved after the procedure, and neonatal complications were not detected. (Korean J Anesthesiol 2012; 62: 579-583)

Key Words: Cesarean section, Pituitary tumor, Pregnancy.

The incidence of brain tumors during pregnancy is rare compared with the incidence in nonpregnant women of the same age [1]. The symptoms of brain tumor including nausea, vomiting, headache, visual disturbances and seizures are mistaken for pregnancy-related hyperemesis or eclampsia. Therefore, diagnosis and treatment could be delayed. In general, surgical treatment for brain tumor during pregnancy is mostly postponed until after delivery. In some cases, surgical treatment is performed earlier and delivery is scheduled later at full term, or both surgical treatment and delivery are carried out during pregnancy. In the case of combined cesarean section and brain surgery, anesthetic plan must ensure both maternal and fetal safety. Rapid sequence induction for cesarean section elevates maternal blood pressure and intracranial pressure, and also hyperventilation and use of mannitol decreases uterine blood flow and induces fetal hypovolemia. Therefore, this circumstance presents a challenge, as it requires a balance of maternal safety and neonatal consideration. In this case,

Received: January 3, 2011. Revised: 1st, February 7, 2011; 2nd, March 4, 2011; 3rd, March 10, 2011. Accepted: March 17, 2011.

Corresponding author: Seong-Chang Woo, M.D., Ph.D., Department of Anesthesiology and Pain Medicine, Eulji University Hospital, 1306, Dunsan-dong, Seo-gu, Daejeon 302-799, Korea. Tel: 82-42-611-3655, Fax: 82-42-482-9036, E-mail: woonoh@eulji.ac.kr

C) This is an open-access article distributed under the terms of the Creative Commons Attribution Non-Commercial License (http:// creativecommons.org/licenses/by-nc/3.0/), which permits unrestricted non-commercial use, distribution, and reproduction in any medium, provided the original work is properly cited. 
simultaneous cesarean section and transsphenoidal surgery for pituitary tumor was successfully performed. Anesthetic management of the case is described and discussed.

\section{Case Report}

A 40-year-old woman $(160 \mathrm{~cm}, 70 \mathrm{~kg})$ at 30 weeks and 4 days of gestation was scheduled for cesarean section and pituitary tumor removal. Her past medical history revealed that she had undergone cesarean section under general anesthesia 10 years ago and her other past medical history was unremarkable. The patient was hospitalized for progressive bitemporal hemianopsia at 23 weeks of gestation. She was diagnosed with pituitary tumor extending into the suprasellar region and the tumor size was $26 \times 21 \times 21 \mathrm{~mm}$. At that time, because of mild neurologic symptoms, low fetal weight, fetal lung immaturity and the possibility of premature birth, the initial decision was to delay the surgery of the pituitary tumor until after delivery at full term. At 30 weeks of gestation, however, she complained of rapidly deteriorating vision and bitemporal hemianopsia in both eyes and the ensuing radiological examination revealed increased tumor size $(28 \times 22 \times 22 \mathrm{~mm})$, displaced tumor location and compressed optic chiasm. Hence, she was scheduled for cesarean section and pituitary tumor resection due to the risk of irreversible blindness. Hormone tests revealed that prolactin, estrogen and progesterone levels were elevated, but these levels were within their normal ranges since she was pregnant. Other blood and biochemical tests were within their normal ranges. And the results of the chest radiography and electrocardiography were also within normal limits. Surgery was scheduled at 31 weeks and 3 days of gestation and neonatal intensive care unit was prepared to render specialized care to the newborn infant.

The patient was premedicated with ranitidine $50 \mathrm{mg}$ and metoclopramide $10 \mathrm{mg}$ intravenously. A left lateral tilt of about $15^{\circ}$ was accomplished to prevent aortocaval compression when the patient arrived in the operating room. $100 \%$ oxygen was administered via a face mask and monitoring of noninvasive blood pressure, electrocardiogram, and pulse oxymetry was started. It showed blood pressure $123 / 72 \mathrm{mmHg}$, heart rate 85 beats/min and 100\% oxygen saturation. Also, a 20-gauge catheter was inserted into her left radial artery for continuous blood pressure measurement and blood sampling. The initial arterial blood pressure was $132 / 60 \mathrm{mmHg}$. Anesthesia was induced by rapid sequence intubation using precurarization technique. First, pretreatment with vecuronium $0.7 \mathrm{mg}$ was started intravenously. After 3 minutes, thiopental $300 \mathrm{mg}$ and succinylcholine $100 \mathrm{mg}$ were administered intravenously to facilitate endotracheal intubation. And then, vecuronium $8 \mathrm{mg}$ was injected intravenously. Immediately after intubation, blood pressure and heart rate were $136 / 72 \mathrm{mmHg}$ and 102 beats/min, respectively. Anesthesia was maintained with $0.8-1.2 \mathrm{vol} \%$ isoflurane, $2 \mathrm{~L} / \mathrm{min}_{2} \mathrm{O}$ and $2 \mathrm{~L} / \mathrm{min}_{2}$. Controlled ventilation was maintained at tidal volume of $8 \mathrm{ml} / \mathrm{kg}$ and respiratory rate of $10-13$ breaths $/ \mathrm{min}$. The end tidal $\mathrm{CO}_{2}$ was measured. After 5 minutes from the time of induction, arterial blood gases revealed $\mathrm{pH}$ 7.35, $\mathrm{PaCO}_{2} 33 \mathrm{mmHg}, \mathrm{PaO}_{2} 110 \mathrm{mmHg}, \mathrm{HCO}_{3}{ }^{-}$ $20.4 \mathrm{mEq} / \mathrm{L}$, base excess $-4.7 \mathrm{mEq} / \mathrm{L}, \mathrm{Hb} 10.4 \mathrm{~g} / \mathrm{dl}$, hematocrit $31 \%$. $\mathrm{FiO}_{2}$ was set at 0.6 to elevate $\mathrm{PaO}_{2}$. After 7 minutes from the time of induction, she delivered a male infant. The neonatal body weight was 2,740 g, one-minute Apgar score was four, and five-minute Apgar score was seven. The infant was then transferred to the nursery. Thereafter, midazolam $2 \mathrm{mg}$ and fentanyl $100 \mu \mathrm{g}$ was administered to maintain anesthetic depth. After placental extraction, $100 \mathrm{ml}$ normal saline containing 20 units of oxytocin was infused and then, 1,000 $\mathrm{ml}$ normal saline containing 10 units of oxytocin was infused slowly to induce uterine contractions throughout the duration of both the obstetric surgery and neurosurgery. Intraoperative hemodynamic and respiratory variables were stable throughout the duration of cesarean section with systolic blood pressure between 100 to $110 \mathrm{mmHg}$, heart rate 70 to 80 beats $/ \mathrm{min}$. Cesarean section lasted for 50 minutes after induction. Arterial blood gases revealed $\mathrm{PaCO}_{2} 32 \mathrm{mmHg}, \mathrm{PaO}_{2} 152 \mathrm{mmHg}, \mathrm{HCO}_{3}{ }^{-}$ $20.1 \mathrm{mEq} / \mathrm{L}$, base excess $-5.6 \mathrm{mEq} / \mathrm{L}, \mathrm{Hb} 8.4 \mathrm{~g} / \mathrm{dl}$, hematocrit $26 \%$. Initially, fluid replacement was done against the intraoperative hemorrhage, but later 1 unit of packed red blood cells was transfused due to continuous bleeding. The estimated blood loss and urine output until the end of cesarean section were $800 \mathrm{ml}$ and $60 \mathrm{ml}$ respectively. $700 \mathrm{ml}$ normal saline and $500 \mathrm{ml} 6 \%$ hydroxyethyl starch (Voluven ${ }^{\circledR}$, Fresenius Kabi, Germany) were administered during cesarean section.

Central venous catheter was inserted into the right subclavian vein for central venous pressure measurement, massive transfusion and fluid replacement before pituitary tumor resection. Otolaryngologist performed the transsphenoidal approach and then, a neurosurgeon resected the pituitary tumor. Anesthesia was maintained with $0.8-1.2 \mathrm{vol} \%$ isoflurane, $2 \mathrm{~L} / \mathrm{min}_{2} \mathrm{O}, 2 \mathrm{~L} / \mathrm{min} \mathrm{O}_{2}$. At the beginning of pituitary tumor resection, arterial blood gases revealed $\mathrm{PaCO}_{2} 30 \mathrm{mmHg}, \mathrm{PaO}_{2}$ $203 \mathrm{mmHg}, \mathrm{HCO}_{3}{ }^{-} 18.0 \mathrm{mEq} / \mathrm{L}$, base excess $-7.4 \mathrm{mEq} / \mathrm{L}, \mathrm{Hb}$ $9.6 \mathrm{~g} / \mathrm{dl}$, hematocrit $29 \%$. During the surgery, arterial blood gases revealed pH 7.35, $\mathrm{PaCO}_{2} 36 \mathrm{mmHg}, \mathrm{PaO}_{2} 242 \mathrm{mmHg}$, $\mathrm{HCO}_{3}{ }^{-} 19.0 \mathrm{mEq} / \mathrm{L}$, base excess $-7.5 \mathrm{mEq} / \mathrm{L}, \mathrm{Hb} 10.1 \mathrm{~g} / \mathrm{dl}$, hematocrit $30 \%$. Hemodynamic variables were well maintained with systolic blood pressure between 90 to $110 \mathrm{mmHg}$, heart rate 70 to 90 beats/min. Cesarean section and brain surgery together lasted for 8 hours after induction. Pituitary tumor located in pituitary fossa was almost completely resected and was diagnosed as pituitary adenoma by histological study. 
Tumor extending into the suprasellar region was not resected via transsphenoidal surgery and was planned to be removed via craniotomy. The estimated blood loss and urine output during pituitary tumor resection were $200 \mathrm{ml}$ and $990 \mathrm{ml}$ respectively. 2,600 $\mathrm{ml}$ normal saline and $500 \mathrm{ml}$ 6\% hydroxyethyl starch (Voluven $^{\circledR}$, Fresenius Kabi, Germany) were administered. At the end of the surgery, cerebrospinal fluid drainage catheter was inserted at the L3-4 interspace and the neuromuscular blockade was reversed with $0.4 \mathrm{mg}$ glycopyrrolate, and 15 mg pyridostigmine intravenously. The patient was extubated fully awake in the operating room and was transferred to the intensive care unit uneventfully. After surgery, the patient was given thyroid hormone and steroids for panhypopituitarism. The patient presented with transient diabetes insipidus, but recovered immediately. On the 4th day after surgery, she was transferred to the general ward. Bitemporal hemianopsia and visual loss mildly improved and she was discharged on the 14th day after surgery. The neonate was healthy and was discharged uneventfully on the 2nd day after delivery.

\section{Discussion}

The most common brain tumor is pituitary tumor in which there is a $15-35 \%$ risk of tumor enlargement during pregnancy $[2,3]$. Brain tumors tend to enlarge during pregnancy due to fluid retention, increased blood flow and hormonal changes [4]. Although the size of the pituitary tumor does not increase, pituitary gland enlarges physiologically with increasing gestational age as a result of the estrogen-stimulated hyperplasia and hypertrophy of the prolactin-producing lactotrophs [5]. Size of up to $12 \mathrm{~mm}$ may be acceptable immediately postpartum [6]. Consequently, the enlarged pituitary gland pushes the preexisting pituitary tumor in an upward direction and therefore indirectly adds to the mass effect [7].

When a parturient needs to undergo brain surgery, the decision to proceed with neurosurgical intervention depends on the neurological symptoms of the mother, emergency of the surgery, possibility of preterm labor, fetal weight, fetal lung maturity and the effects of mannitol and hyperventilation influencing the fetus. Surgery for slow-growing benign tumor such as meningioma can be delayed until after delivery depending upon periodical physical and neurologic examination, but a malignant tumor and a rapidly growing benign tumor must be removed despite pregnancy [1].

In this case, when the patient was diagnosed with pituitary tumor, she would not have undergone surgery for pituitary tumor until after cesarean section at full term, but she complained of aggravation of the symptoms of bitemporal hemianopsia and visual loss due to increased tumor size at 30 weeks of gestation. Therefore, she was planned for surgery of pituitary tumor due to the risk of irreversible blindness. We discussed the possibility of maintenance of pregnancy during neurosurgery with an obstetrician. The planned day of surgery was at 31 weeks and 3 days of gestation and the simultaneous cesarean section and pituitary tumor resection was electively undertaken in consideration of acquisition of some fetal lung maturity and viability the possibility of fetal asphyxia and preterm labor due to the long duration of anesthesia, and the effect on uterine contractions which result from disorder of oxytocin secretion in the posterior lobe of pituitary gland due to pituitary tumor resection.

The management of combined neurosurgical anesthesia and general anesthesia for cesarean section as in this case requires a comprehensive knowledge of physiology in the mother and the fetus, and of physiology and pharmacology of neurosurgical anesthesia for ensuring safety in both, the mother and the fetus. In neurosurgical anesthesia, endotracheal intubation should be facilitated carefully due to increase of blood pressure and intracranial pressure. Especially, rapid sequence induction using succinylcholine commonly performed during general anesthesia for cesarean section dramatically induce hemodynamic changes and hence an increase in intracranial pressure [8]. In a combined case like this one, it is thought that use of succinylcholine for muscle relaxation only should be avoided before endotracheal intubation. To prevent fasciculation, precurarization technique can be performed using $10-15 \%$ of nondepolarizing neuromuscular blocking agent administered 5 minutes before injection of succinylcholine. It can also be performed in another way by the priming principle using a priming dose. By giving $10-15 \%$ of the usual intubating dose 5 minutes before induction, paralysis will quickly follow when the balance dose of relaxant is administered. Use of a priming dose can produce conditions suitable for intubation in as soon as 60 seconds following administration of rapid-acting nondepolarizer such as rocuronium, or in 90 seconds following administration of intermediate-acting nondepolarizer such as vecuronium or atracurium [9].

Inhalational anesthetics such as isoflurane, sevoflurane and desflurane are safe in general anesthesia for cesarean section and all inhalational anesthetics including $\mathrm{N}_{2} \mathrm{O}$ can elevate intracranial pressure as a result of cerebral vasodilation but it can be reversed by hyperventilation [10]. Not using $\mathrm{N}_{2} \mathrm{O}$, and using high concentrations of inhalational anesthetics to maintain anesthetic depth elevates intracranial pressure and inhibits uterine contractions which can induce obstetric hemorrhage. Therefore, anesthetic depth can be achieved by inhalational anesthesia using $\mathrm{N}_{2} \mathrm{O}$ or balanced anesthesia using inhalational anesthetic with an opioid and benzodiazepine. Also, uterotonic agents need to be administered to prevent obstetric hemorrhage. However, ergotamine and prostaglandins 
elevate intracranial pressure due to increase in blood pressure. Therefore in this combined case of obstetric and neurosurgical anesthesia, oxytocin is the ideal uterotonic agent [11]. In this case, gestational age was 31 weeks and 3 days and estimated fetal weight was 2,000 g. Therefore, due to the risk of respiratory depression, inhalational anesthesia was performed using $\mathrm{N}_{2} \mathrm{O}$ without an opioid and benzodiazepine and oxytocin was also administered throughout the duration of neurosurgery after cesarean section. Consequently, uterine contractions were maintained appropriately and the intraoperative hemodynamic variables were stable.

In the case of neurosurgical anesthesia, hyperventilation is performed to reduce cerebral perfusion, to create a good view of the surgical field and to make the surgical manipulation easier. Hyperventilation can decrease uterine blood flow due to reduced venous return caused by elevation of intrathoracic pressure. Also, hypocapnia caused by hyperventilation reduces uterine blood flow and induces shift of the $\mathrm{O}_{2}$-hemoglobin dissociation curve to the left, thus inducing fetal acidosis by decreasing $\mathrm{O}_{2}$ delivery to the fetus [12]. Therefore, ventilation should be performed appropriately in view of the effect of hyperventilation which has an influence on both the mother and the fetus. It is necessary to evaluate the appropriateness of hyperventilation according to the measurement of end tidal $\mathrm{CO}_{2}$ and arterial blood gas analysis. Generally, if the end tidal $\mathrm{CO}_{2}$ is in the range of $25-30 \mathrm{mmHg}$, there is no adverse effect on the fetus and hyperventilation is maintained appropriately in the parturient [12]. In this case, the tumor did not seriously invade the brain parenchyma and there were no signs and symptoms of increased intracranial pressure. However, we regulated the tidal volume and respiratory rate to maintain the uterine blood flow and to reverse the increased intracranial pressure caused by inhalational anesthetics and fluid replacement against blood loss during cesarean section. The $\mathrm{PaCO}_{2}$ was maintained at an average value of $33 \mathrm{mmHg}$.

Fluid replacement should be performed based on the urine output, insensible loss, and blood loss during surgery. If plasma osmotic pressure is not decreased and is well maintained, the risk of elevation of intracranial pressure and cerebral edema is rare. Crystalloids should be given at 3 times the estimated volume of blood loss and colloid should replace the same volume of blood loss. Because ideal oxygen delivery capacity is maintained at hematocrit of $30 \%$, transfusion should be planned when hematocrit is severely decreased [13]. In this case, crystalloid and colloid solutions were given throughout the duration of surgery. Although, we did not perform the test for plasma osmotic pressure, according to the intermittently performed arterial blood gas analysis it was suggested that plasma osmotic pressure be maintained within the level of the preoperative value. Therefore, it was thought that the risk of elevation of intracranial pressure and cerebral edema was rare, and the occurrence of this possibility was less with hyperventilation.

In the past, diuretic effect of mannitol was shown to induce fetal dehydration, but a recent study showed that the use of $0.5-1.0 \mathrm{~g} / \mathrm{kg}$ of mannitol is clinically safe [14]. Also, steroids are commonly used to reduce intracranial pressure and cerebral edema, and the short-term use of steroids does not induce significant adverse effects and has an advantage of inducing fetal lung maturation as a result of increase in the production of surfactant in the fetus [15].

In conclusion, when cesarean section is performed in a parturient with brain tumor, the time of delivery and decision of combined surgery is planned in view of the location and pathology of brain tumor, clinical symptoms, gestational age, fetal lung maturity and viability. Using the comprehensive knowledge of the physiology and pharmacology of the mother and the fetus, careful anesthetic management should be tailored for the control of intracranial pressure and safety of the mother and the fetus, based on the understanding of the contradictions between neurosurgical anesthesia and general anesthesia for cesarean section.

\section{References}

1. Chandraharan E, Arulkumaran S. Pituitary and adrenal disorders complicating pregnancy. Curr Opin Obstet Gynecol 2003; 15: 101-6.

2. Swensen R, Kirsch W. Brain neoplasms in women: a review. Clin Obstet Gynecol 2002; 45: 904-27.

3. Tewari KS, Cappuccini F, Asrat T, Flamm BL, Carpenter SE, Disaia PJ, et al. Obstetric emergencies precipitated by malignant brain tumors. Am J Obstet Gynecol 2000; 182: 1215-21.

4. Goldberg M, Rappaport ZH. Neurosurgical, obstetric and endocrine aspects of meningioma during pregnancy. Isr J Med Sci 1987; 23: 825-8.

5. Scheithauer BW, Sano T, Kovacs KT, Young WF Jr, Ryan N, Randall RV. The pituitary gland in pregnancy: a clinicopathologic and immunohistochemical study of 69 cases. Mayo Clin Proc 1990; 65: 461-74.

6. Elster AD, Sanders TG, Vines FS, Chen MY. Size and shape of the pituitary gland during pregnancy and post partum: measurement with MR imaging. Radiology 1991; 181: 531-5.

7. Masding MG, Lees PD, Gawne-Cain ML, Sandeman DD. Visual field compression by a non-secreting pituitary tumour during preganacy. J R Soc Med 2003; 96: 27-8.

8. Lee WH, Choi SJ. The effect of succinylcholine on the intracranial pressure in cats. Korean J Anesthesiol 1990; 23: 187-99.

9. Morgan GE Jr, Mikhail MS, Murray MJ. Clinical anesthesiology. 4th ed. New York, McGraw-Hill companies. 2006, pp 216-7.

10. Barash PG, Cullen BF, Stoelting RK. Inhlation anesthesia. In: Clinical Anesthesia. 5th ed. Edited by Ebert TJ: Philadelphia, Lippincott Williams \& Wilkins. 2006, pp 397-401.

11. Lee HK, Jeon SH, Sohn JT, Shin IW, Chung YK. General anesthesia 
for a cesarean section in a patient with a brain tumor. Korean J Anesthesiol 2002; 43: 515-9.

12. Johnson MD, Zavisca FG. Intracranial lesions. In: Obstetric Anesthesia and Uncommon Disorders. Edited by Gambling DR, Douglas MJ: Philadelphia, W.B. Saunders company. 1998, pp 230-1.

13. Cottrell JE, Smith DS. Intraoperative fluid management during craniotomy. In: Anesthesia and Neurosurgery. 4th ed. Edited by
Zornow MH, Scheller MS: Philadelphia, Mosby. 2001, pp 237-49.

14. Babara AD, Rosen MA. Anesthesia for neurosurgery during pregnancy. In: Anesthesia for obstetrics. 4th ed. Edited by Shinider SM, Lebinson G: Baltimore, Williams \& Wilkins. 2002, pp 509-28.

15. Isla A, Alvarez F, Gonzalez A, Garcia-Grande A, Perez-Alvarez M, Garcia-Blazquez M. Brain tumor and pregnancy. Obstet Gynecol 1997; 89: 19-23. 